\title{
New opportunities in a mature oil field: Stretching data interpretation for complex reservoir prediction
}

\author{
Evelin Márquez*; Fábio Berton; Ana Carolina Stevanato; Fabiana Chaves; Nikolai Ojevan, Equinor Brasil
}

\section{Copyright 2021, SBGf - Sociedade Brasileira de Geofísica}

This paper was prepared for presentation during the $17^{\text {th }}$ International Congress of the Brazilian Geophysical Society held in Rio de Janeiro, Brazil, 16-19 August 2021.

Contents of this paper were reviewed by the Technical Committee of the $17^{\text {th }}$ International Congress of the Brazilian Geophysical Society and do not necessarily represent any position of the SBGf, its officers or members. Electronic reproduction or storage of any part of this paper for commercial purposes without the written consent of the Brazilian Geophysical Society is prohibited.

\begin{abstract}
The combination of complex geology and limited seismic resolution results in high uncertainties for the prediction of reservoir distribution in subsurface, impacting the planning of the drainage of the reservoir and the well placement within it. In the Peregrino heavy oil field (Campos Basin, SE Brazil), these conditions motivated the use of multiple approaches of seismic analysis and interpretation coupled with conceptual geology to find new opportunities in a mature field and to reduce the risks for the placement of oil producer wells. The methods include seismic geomorphology of both reservoir and substrate to map sediment bodies, seismic forward modelling, and wedge modelling to estimate thicknesses, and correlation of the seismic data with geological interpretation from wells and conceptual models. The reservoir in the area is composed by channelized turbiditic sandstones deposited in an upper slope setting during Late Cretaceous. The main challenges for well placement are the gradual thinning of the reservoir towards the pinch-out zone, the change of sedimentary facies from downdip to updip, and the exact limit of the pinch-out. The substrate also imposes a complexity to the reservoir, as its morphology influenced sandstone distribution in the area. Three producer wells were drilled under these conditions. They not only proved the potential of the area, but their results also shown an excellent correlation with the geological features interpreted in multiple attribute maps. Such results give more confidence in pushing the limits of seismic interpretation, and bring valuable lessons for the future of mature fields.
\end{abstract}

\section{Introduction}

The effective drainage of an oil field highly depends on the position of producer wells in relation to the reservoir, but in complex geological conditions with limited seismic resolution the distribution of reservoir in subsurface might be hard to predict. Such combination of factors results in high uncertainties for well placement, and an integrated approach for subsurface analysis becomes necessary to secure that the reservoir targets are achieved. The case study presented here shows the process of planning and the results of three successful horizontal oil producer wells drilled in an area below seismic resolution and with limited well correlation in the Peregrino oil field (Fig. 1). Multiple approaches of seismic interpretation coupled with conceptual geology were key to find new opportunities in a mature field, reinforcing the importance of seismic analysis even in areas well covered by subsurface data. The Peregrino field is located in south Campos Basin, in the Brazilian southeastern continental margin (Fig. 1). The reservoir is composed by multi-darcy sandstones from the Carapebus Fm., deposited between the Campanian and Maastricthian as turbidites in an openmarine slope setting. The sand-rich turbidites are covered by deep-marine shaly intervals from the Tamoios Mbr., forming a stratigraphic trap. Since 2011 the field produced almost $200 \mathrm{MMbbl}$ of low-API viscous oil, and $\sim 70 \%$ of the current production comes from the Southwest segment where the wells shown in this study were drilled (Fig. 1).

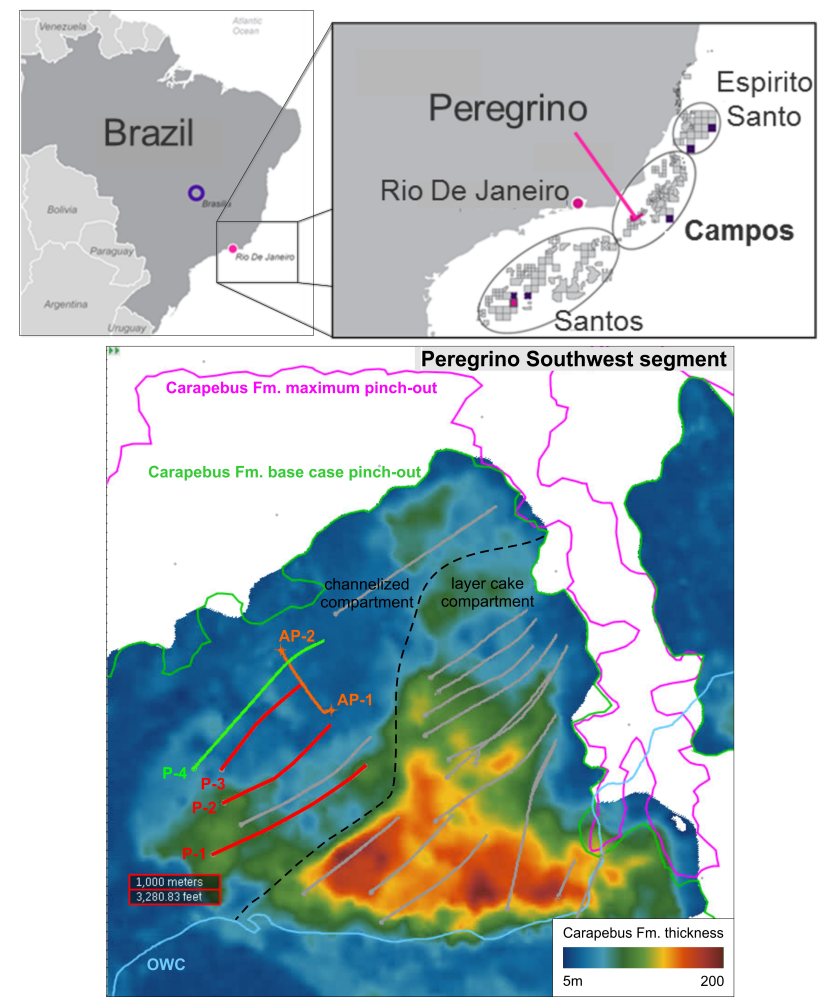

Figure 1: Location of the Peregrino oil field in Campos Basin and map of Carapebus Fm. thickness in the Southwest segment of the field.

The Southwest segment of Peregrino field is subdivided in two geological compartments. The thicker compartment is composed by channel to frontal splay turbidites disposed in a layer-cake stacking pattern (Fig. 1). This area is well resolved by seismic data and was the target of the first wells on the segment. The thinner 
compartment is updip of the layer-cake (Fig. 1), in a zone mostly below seismic resolution. Reservoir presence is indicated indirectly in seismic amplitude maps and proved by two appraisal wells, but in this updip area Carapebus Fm. thins out due to a wedge macro geometry and pinches out against the paleoslope. Reservoir presence is uncertain, and seismic tuning becomes a great challenge to interpreters. 2D seismic forward modelling and wedge modelling are extensively used to understand the seismic signature and to define pinch-out limits based on both quantitative and qualitative approaches (Fig. 1). These limits reflect the confidence in the seismic data to base geophysical and geological evaluations prior to the placement of horizontal wells. In such conditions the interpretation of the substrate onto which the reservoir is settled is also crucial to foresee risks. The surface morphology of the carbonates from the Albian Macaé Group strongly influences the distribution of the overlying Carapebus Fm. turbidites, controlling the formation of feeder channels, bypass zones, structural highs and depocenters. These features are analyzed mainly through seismic geomorphology and discontinuity and correlated with the signatures in attribute maps from the reservoir. This investigative approach considers the redundancy of results from seismic interpretation of reservoir and associated units and their correlation with well data and geological concept as the key for well placement in a zone below seismic resolution.

\section{Materials}

The subsurface of the Peregrino field is covered by 3-D broadband seismic data and vertical and horizontal wells. Post-stack depth-migrated seismic volumes are mostly used for interpretation and generation of seismic attributes. In general, seismic interpretation uncertainty to identify sandstone bodies and potential baffles has been reduced in the past years due to less tuning, with a direct impact in the total field reserves calculation. Before drilling horizontal wells, seismic uncertainty has also been reduced significantly by the presence of existing appraisal wells.

Appraisal wells AP-1 and AP-2 proved reservoir presence in the area as sandstone beds up to $12 \mathrm{~m}$ thick. Core interpretation indicated that the reservoir bodies are channelized turbiditic sandstones from the uppermost Carapebus Fm. Three producer wells were then drilled crossing this reservoir, and the data acquired while drilling added valuable information to the field. Besides the conventional set of well logs that include gamma-ray, density, neutron and resistivity logs, the producer wells also have logs used to support geosteering operations (e.g., density image, resistivity image, and ultra-deep resistivity inversions).

The resistivity inversions used to support geosteering are especially useful to image sediment bodies in the order on 10's of $\mathrm{m}$ around the borehole. In a horizontal well they represent the link between seismic and well scales, allowing evaluations of reservoir geometry, architecture, lateral connectivity of reservoir bodies and reservoir compartmentalization. Their scale of visualization makes them easily to correlate with trends in seismic attribute maps, reducing considerably the uncertainties in seismicgeomorphologic interpretations (Fig. 2).

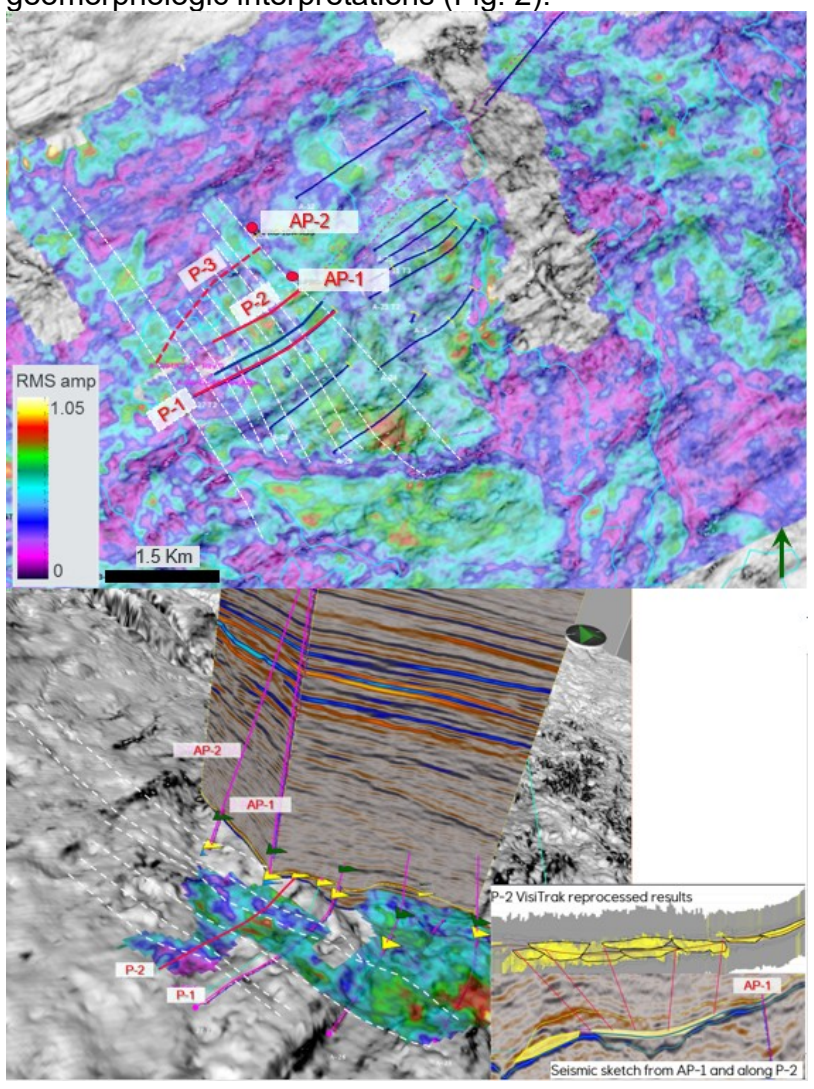

Figure 2: Combined amplitude RMS map of Southwest segment updip indicate the distribution of sandstone bodies. Integration and correlation of P-1 and P-2 ultradeep resistivity inversions and combined geological and geophysical analysis made possible the planning of $\mathrm{P}-3$ further updip.

\section{The Well Planning Process}

The standard producer well design for the Peregrino field considers NE-SW horizontal wells that cut the turbidite bodies transversally and navigate parallel to the Carapebus Fm. beds. The objective of this design is to cross as many reservoir bodies as possible within the same stratigraphic unit without crossing non-reservoir formations, and to avoid crossflow between different reservoir levels. The planning process seeks for the optimal well placement within a drainage area, considering the geological conditions, subsurface uncertainties, and operational limitations. The first step in planning a well is to understand which reservoir bodies must be crossed to secure the drainage. The mapping of those bodies is usually done through the interpretation of attribute maps, and the correlation of these interpretations with existing wells is key to complete the area puzzle. Logs play an important role into the prediction of facies content, as well as the ultra-deep resistivity inversions.

Carapebus Fm. seismic surfaces are generally studied through amplitude and frequency attributes using relevant 
time windows to identify potential channel morphologies. The attribute maps will indicate indirectly the variations of composition, the size and geometry of the sediment bodies, and possible geological risks. Optical slicing and spectral decomposition are also used to give more confidence in the interpretation. The seismic attributes applied on the Macaé Gp. top surface are generally related to the discontinuity of the seismic signal, generating semblance maps where the erosive character of the Carapebus Fm. channels is partially preserved. A seismic detuning workflow is used to extract meaningful thickness information of the zone below seismic resolution, together with geo-statistical methods based on the well results. After the location of the well is defined, a more detailed plan is made to guide the geosteering during drilling. As the vertical seismic resolution is of $\sim 25 \mathrm{~m}$ at best, the geosteering plan must consider the possible geological scenarios and risks considering the vertical seismic uncertainty, which are built from the correlation of attribute maps with wells nearby.

\section{Results}

Carapebus Fm. porous unconsolidated sandstones from Peregrino field correspond to a low acoustic impedance rock signature compared to higher acoustic impedance signatures of both overlying and underlying rocks. The acoustic contrast with fine-grained sediments of the Tamoios Mbr. above and the carbonates of Macaé Gp. beneath Carapebus Fm. make these sandstones shine as its interfaces are detected by seismic reflection methods. These soft sandstones are typically highlighted in amplitude maps such as instantaneous and/or as maximum negative amplitude when a representative TWT window is selected (typically $16-24 \mathrm{~ms}$ ).

Seismic interpretation of top reservoir on pick strong and continuous throughs or negative reflectors (SEG polarity convention) assuming a litho-stratigraphic interpretation has been more efficient in Peregrino than a more conventional chronostratigraphic interpretation. This type of interpretation often mixes the timing of different turbiditic pulses. In the updip setting of Peregrino where seismic resolution is at its limit, two or more seismic reflectors become one as reservoir pinches-out. Mapping different levels and then merging this interpretation updip can bring continuity to seismic features that do not have much geological meaning when truncated and only interpreted up to their resolution extend. A patch work of several amplitude maps is often performed to present attribute maps in the south-west area of the field.

Well-ties from appraisal wells AP-1 and AP-2 confirmed a strong correlation of the presence of sandstones and a solid trough (negative reflector), even when the gross thickness of the reservoir is close to or below seismic resolution. This means sandstones are detected even if top and base are not fully resolved by the seismic method. Peregrino seismic datasets resolution varies slightly from area to area but in average tuning thickness is around $30 \mathrm{~m}$. Seismic tuning becomes a challenge to estimate gross thickness and furthermore net thickness becomes almost an unthinkable quest. However, a seismic detuning workflow described by Simm (2009) has been applied to this area with certain degree of success and results of horizontal wells have proven useful to calibrate this geophysical quantitative approach. Map of pseudo-thickness trends from Fig. 3 can be used as a proxy for net thickness. In this workflow composite amplitudes (the sum of the absolute amplitudes of top and base reservoir) and their relationship with TWT thickness is investigated for thicknesses below the seismic tuning for a particular dataset. Seismic wedge modelling is then used to investigate how well results can help to validate actual and apparent thickness relationships.

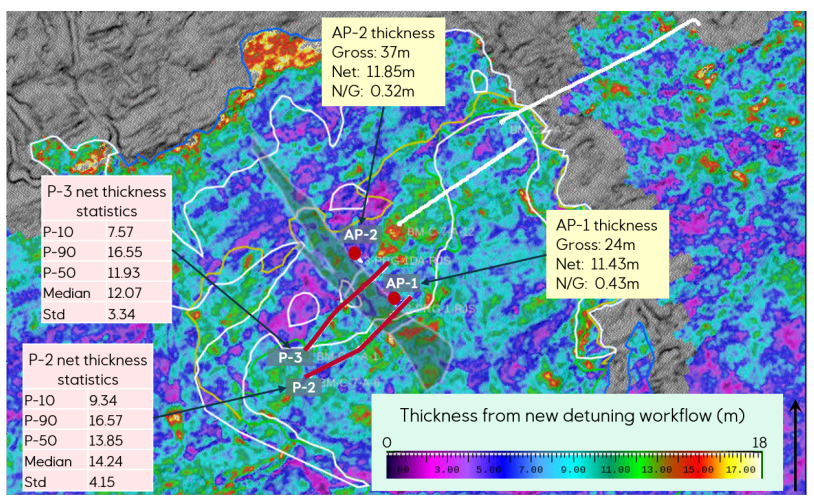

Figure 3: Pseudo-thickness trends from detuning workflow, valid inside white polygon where seismic tuning exists, correlates well with appraisal and horizontal net thickness estimations (a statistical simulation approach helped to represent values from horizontal wells). Gray polygon represents channel complex 1 with reservoir thickness estimated by other geostatistical methods that also correlates with this map. See how AP-1 and AP-2 are located at the border of CC1 with net thickness < $12 \mathrm{~m}$.

Both spectral decomposition and optical slicing are used methods that measure seismic frequency that have also given good results in this updip setting. Qualitatively they highlight thin beds which geomorphologies that also match with seismic amplitudes. The interpretation of amplitudes within a TWT interval and instantaneous amplitude maps of Carapebus $\mathrm{Fm}$. indicated the presence of NW-SE turbidite channel complexes (Fig. 2), but the combined interpretation of spectral decomposition and optical slices and their correlation with the top Macaé surface morphology allowed the ultimate definition of three channel complexes (CC1-CC3) with low sinuosity and controlling the connectivity along dip of the sand bodies (Fig. 2).

The first producer well drilled in the thinner compartment of Peregrino Southwest was P-1, aiming for the channel complexes in a zone still resolved by seismic resolution. It proved the geological concept of channelized turbidites in the area, and the geological compartment was thus renamed to 'channelized' (Fig. 1). The channels crossed by $\mathrm{P}-1$ are amalgamated and up to $25 \mathrm{~m}$ thick, grouped in three channel complexes (CC1-CC3) (Fig. 4).

The second well (P-2) was drilled updip of P-1, partially in a zone below seismic resolution. It not only reinforced the 
geological interpretation of turbidite channels, but also proved the existence of prolific reservoir bodies in the zone below seismic resolution, motivating the revision of the base case Carapebus pinch-out limit (Fig. 1). Only CC1 and CC2 were crossed by P-2, with $10 \mathrm{~m}$ and $20 \mathrm{~m}$ thick, respectively. There is a strong correlation between the results from the deep-azimuthal resistivity inversions and seismic attribute maps (Fig. 4), which supported the planning of the third producer well drilled in the area.

P-3 identified discrete channels up to $10 \mathrm{~m}$ thick in CC1, and more than $20 \mathrm{~m}$ thick channels in CC2. Again, a good correlation between well results and attribute maps was noticed in this well (Fig. 4). Neither P-2 nor P-3 could reach $\mathrm{CC} 3$ due to operational limitations, but their results indicate that there is still reservoir potential further updip in the zone below seismic resolution. Gross reservoir thickness is still considerable (up to $20 \mathrm{~m}$ thick) and attribute maps indicate the extension of the channel complexes upslope, motivating the planning of a fourth well (P-4) to be drilled later in 2021.
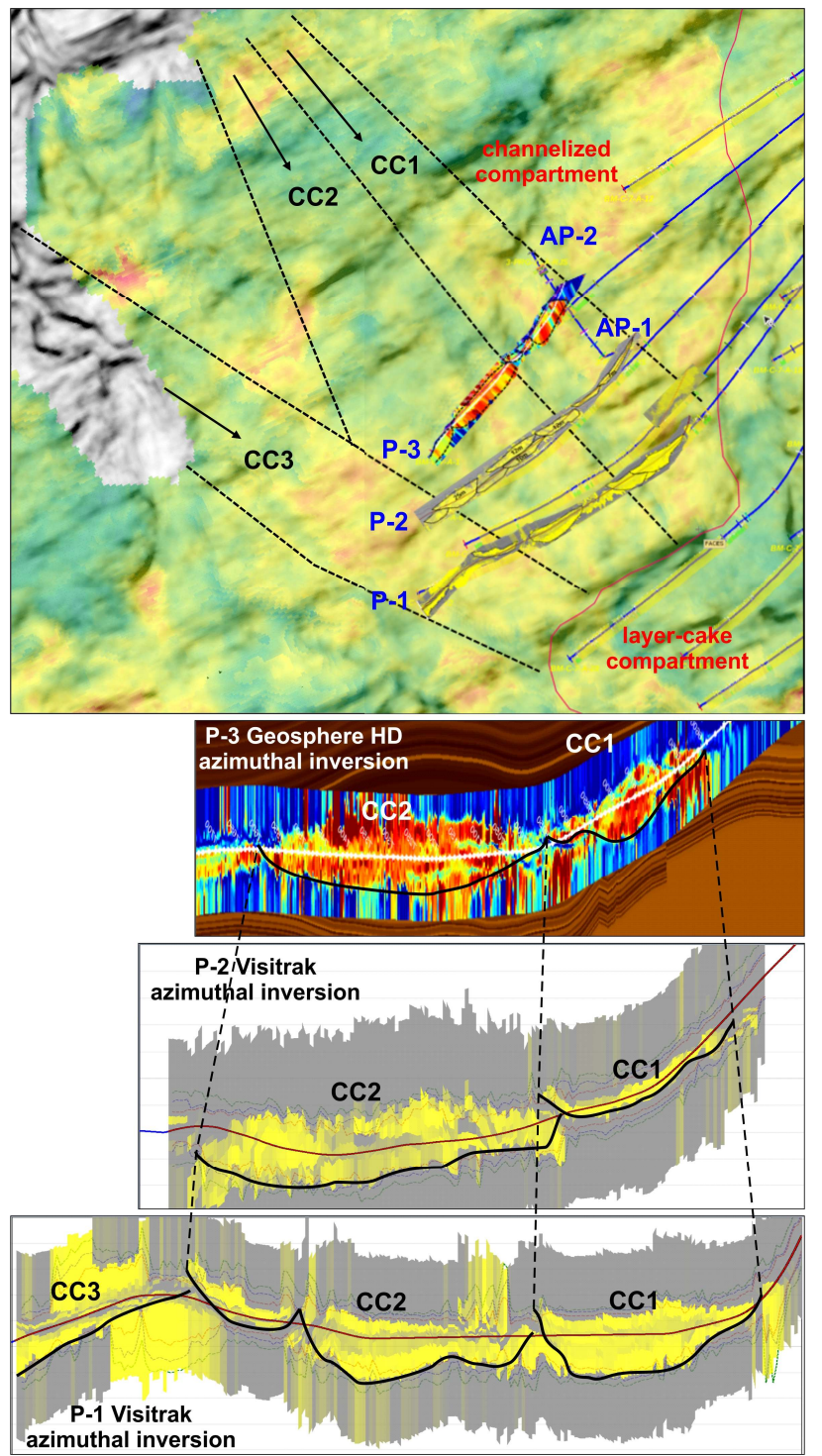

Figure 4: Top Carapebus Fm. Instantaneous Amplitude map shaded on top Macaé Gp. Semblance map (warm colors represent largest negative amplitudes). The interpretation of channel complexes from multiple attribute maps show a good match with well results, illustrated here by the ultra-deep resistivity inversions. Geosphere HD inversions are provided by Schlumberger, while Visitrak inversions are provided by Baker-Hughes.

\section{Discussions and Conclusions}

The results of the three producer wells indicate the value of using multiple approaches of seismic analysis and interpretation to evaluate the potential in areas below seismic resolution. The redundancy of geological interpretations using different seismic attributes at reservoir level is essential to map sediment bodies and determine their architecture. This was exemplified by the mapping of NW-SE channelized features in amplitude maps, spectral decomposition maps and optical slices, which had good correlation with the well results. In the case of the Peregrino turbidites, the use of seismic geomorphology on the top Macaé Gp. surface was also essential to link the potential sediment bodies deposited in Carapebus $\mathrm{Fm}$. with their conduits carved on the paleoslope. The combination of those different types of evidence gives more confidence on the geological interpretation that serves as a basis for well placement.

Despite the good results of the wells planned through this multi-disciplinary approach, another level of detail has been necessary to understand the conditions and risks for new wells in the channelized compartment. The attribute maps give good hints about reservoir presence, but the properties of the reservoir remain uncertain. In a mature oil field such as Peregrino the remaining opportunities are in non-drilled areas near the formation pinch-out, where the reservoir is thinner and usually below seismic resolution. The greatest challenge for seismic interpreters is to define how far updip it is possible to go to guarantee economical producer wells. Natural geological changes are expected in this domain of the turbidite systems, affecting the size, geometry and composition of the sediment bodies (Prather et al., 2017). Turbidite channels closer to the paleoslope tend to be more confined and susceptible to the substrate morphology. Lateral connectivity of reservoir bodies becomes lower than in downdip areas, and a change of facies is expected within the reservoir. These geological variations must be accounted during well planning, as they can affect reservoir potential and operational risks. Well P-3, for instance, experienced several operational challenges during drilling because of the presence of conglomeratic intervals that are typical of proximal turbidite deposits. Targets further updip such as P-4 will probably face similar issues during drilling.

Seismic-geomorphological analysis of both channel feeders carved in the slope and channel systems that configure reservoir in Carapebus $\mathrm{Fm}$. bring valuable information to the prediction of the reservoir properties. The sinuosity of channel features internal to the channel complexes in attribute maps, for instance, can give clues to the geologists about the internal distribution of 
sedimentary facies (e.g., Kane et al., 2008). The width of both channels and channel complexes can be used to estimate sandbody thickness through geostatistical methods (e.g., Moscardelli and Wood, 2016). Seismic detuning workflow alongside with forward modelling and wedge modelling can help in the identification of safe and critical areas in terms of reservoir thickness and presence (Simm, 2009). The results from these different methods can be confronted against geostatistical methods of reservoir estimation from well results to validate the interpretations, and the lessons can be taken to other parts of the field. Peregrino Phase 2 will be on stream during the first half of 2022, and much of the experience acquired in the channelized compartment of Peregrino Southwest served as a base to plan its drainage (Haugen et al., 2015). The near-pinch out areas below seismic resolution are no longer seen as a frontier for economical wells, but as an opportunity to be explored since the very beginning of the new phase of field development.

\section{Acknowledgments}

The authors acknowledge Equinor Brasil and Sinochem for allowing the publication of the subsurface data shown here and in the presentation. We would also like to thank our colleagues from Subsurface Brazil and Production Technology Peregrino, whose contribution was essential to decrease uncertainty and to unlock further updip potential in the south-west part of the field. In addition, the authors acknowledge PGS, proprietary of Peregrino seismic datasets.

\section{References}

Haugen, E., Østbye, N.O., Grønvold, T., Straith, K., Theting, T.G. 2015. Lessons learned from further development of the Peregrino heavy oil field offshore Brazil. Society of Petroleum Engineers, SPE-174341-MS.

Kane, I.A., McCaffrey, W.D., Peakall, J., 2008. Controls on sinuosity evolution within submarine channels. Geology, 36(4), 287-290.

Moscardelli, L., Wood, L. 2016. Morphometry of masstransport deposits as a predictive tool. GSA Bulletin, 128, 47-80.

Prather, B.E., O’Byrne, C., Pirmez, C., Sylvester, Z. 2017. Sediment partitioning, continental slopes and base-ofslope systems. Basin Research, 29, 394-416.

Simm, R. 2009. Simple net pay estimation from seismic: a modelling study. First Break, 27, 45-53. 